\title{
Selecting an Advisor: Professional and Personal Considerations
}

Chris Macaulay, Mary McThomas, and Alisson Rowland

\section{Introduction}

For graduate students, no individual is as important to their education or career as their advisor. Virtually all graduate programs require that students select a "committee chair," whose formal job is to serve as the leader on their dissertation committee. However, beyond this formal role is the informal role of advisor throughout the entire graduate school process, from the earliest stages of taking classes, guiding the student through comprehensive exams, crafting and editing their dissertation and, ultimately, helping the student find employment. Finding an advisor who can fulfill all these roles can be difficult, and graduate students should consider each of these roles as they seek and assess potential advisors.

Given the crucial nature of this position, and its centrality to every aspect of the graduate school experience, there are few decisions as impactful as a graduate student's choice of advisor. This chapter will offer advice for graduate students in making this decision, outlining the importance of factors such as a potential advisor's prestige and expertise, ability to commit time to their students, ability to foster publications, capability to provide emotional and moral support, and the degree to which they help network and build the professional career of their advisees. This chapter will further explore the need to have multiple individuals fill the above roles, and address some of the potential inequities and issues that can face students in the advisor-advisee relationship.

\section{Picking an Advisor}

The choice of an advisor can understandably be difficult, and often students are given little direction in the process. Many institutions require a choice to be made early and formally, while others wait until the dissertation stage to require such a formal commitment. While it remains a perfectly acceptable option to change advisors at any point during graduate school, repeated changes may be undesirable and impede graduation, and thus it is advisable to find a good fit for advisor as soon as possible.

One of the most used tactics by departments when deciding which students to admit to their department is how well their research aligns with current faculty. Research fit can be incredibly helpful in choosing who to work with. However, be cautious about this being the sole deciding factor in a mentor relationship. While you may share the same substantive focus as a faculty member, it is highly unlikely you will be using the same methodologies and frameworks as them, or be asking the same questions. Depending on the type of research you will be conducting, it is 
important to consider what your strengths and gaps are to know where mentoring will be the most appropriate. This may require talking to multiple professors and basing an advising relationship on factors aside from research fit.

While there are many factors to consider when choosing an advisor, students are often tempted to select an advisor with significant name recognition and influence, but in doing so must consider their overall availability. Choosing a prestigious or well-known advisor may be beneficial, as prestigious advisors may carry with them some weight on the job market, and may be able to assist a student in networking and building their future career. This is particularly helpful when they share a similar research interest or subfield as the advisee, as their familiarity with their work will only serve to enhance the eventual dissertation. However, other factors must be considered, as advisors with considerable prestige may also have considerable time commitments beyond advising, limiting a student's ability to benefit from their tutelage. Particularly for newer professors and those seeking either tenure or promotion, the commitments of research on top of teaching and service may limit an advisor's availability, and potentially lower their available time as well as the overall quality of their advice.

It is thus advisable for graduate students to investigate the reputation of potential advisors, by speaking to their current advisees, colleagues, and others familiar with their personality and availability. One unfortunate factor to consider is the faculty member's reputation and track record of working with non-traditional students. As discussed below, unconscious bias can lead to false determinations about a student's ability. This, in turn, can translate into an advisor paying that student less attention. Often, potential advisors are more eager to expand their pool of advisees while others have pre-existing advising commitments or little time due to other academic demands, and understanding this should help inform graduate students' choices.

Habits of good advisors are many, and can be improved and expanded at the suggestion of the advisee. These habits include regular meetings to maintain contact, updating an advisor regularly on progress made at every stage of graduate school, not only during the dissertation writing process. These can be excellent opportunities to begin collaborative work, ensure continued progress on non-dissertation endeavors, plan for conferences and networking, and find emotional and social support that might otherwise be lacking. Ultimately, inquiring whether advisors have engaged in these habits with previous advisees, and suggesting and reinforcing them once the advisor is chosen, are vital to ensuring success in graduate school.

\section{Networking}

As with other professions, forming connections with those more senior in your field is essential for your growth and success. Your advisor plays a critical role in helping you shape your academic network in several ways. Conferences are a very common method for networking, and having your advisor attending with you, at least for the first few, can aid in positive conference experiences by introducing you to others doing similar research. These relationships may lead to further opportunities, such as invitations to chair panels, to work on collaborative projects, and sometimes even for job postings. While conferences are one avenue for such opportunities, there are less formal spaces to create these connections. Your advisor will have a much broader 
network due to their experience in the field, and they will be made aware of calls for proposals or grant applications, and should be forwarding these to you for you to either pursue or not. It is important to recognize that the advisor-advisee relationship is mutually beneficial, benefiting the advisor as well as advisee. Advisees should endeavor to assist their advisors in research projects, bolstering their publications and learning vital aspects of the research process, and otherwise demonstrate their skills and abilities. Advising itself provides considerable value to the advisor, and the gratitude and demonstrated effort of an advisee will only continue to benefit both parties. That said, it is important for advisees to ensure they are not being exploited in this process - advisees should ensure adequate representation in publications and other endeavors. This means ensuring that advisees are accurately and appropriately represented as author in any publication, commensurate with their efforts. Under no circumstances should an advisor pressure an advisee to complete tasks or otherwise assist them without compensation. The ultimate goal of an advisor is to assist a graduate student in graduating and finding employment - any tasks that go against this goal should be resisted, reported, and a new advisor should be sought.

\section{Long-term Goals}

An additional consideration when picking an advisor is that of long-term professional goals. This can be an incredibly important factor in a supportive mentoring relationship. Even if you are not sure early on in your academic career what your plans are, consulting your advisor can help shape your path and direct you towards helpful resources. On the other hand, if you find your long-term goals shifting, this may direct you towards other faculty and that is completely normal and expected.

Being clear with your expectations for a mentoring relationship, knowing that research fit fluctuates as your research progresses, and being open to consulting other people as your longterm goals solidify are all important aspects to consider as your relationship with your advisor progresses.

\section{Communication}

Building a professional rapport with an advisor is extremely helpful. However, issues can arise with your advisor, even when they are providing all the benefits listed above. Advisors have varied styles just as students have different needs. For example, one student may want their advisor to proactively contact her to check in on her progress; another may find this anxiety-inducing and prefer to connect with her advisor only when she has something to discuss. Similarly, some students prefer weekly meetings while others find such regular meetings too burdensome. It is crucial to communicate your needs and preferred style to your advisor. Some programs use advisor contracts where both the student and faculty member indicate their expectations and commitments. A more informal discussion can satisfy this goal as well.

It is important to be realistic about what your advisor can and is willing to do. It may be that your preferred primary advisor is not willing to take on a more intense mentorship, especially if they have multiple advisees. It is then up to you to decide if it is worth it to stay with that person (for 
the reasons discussed above), find another primary advisor, or ask additional faculty members (perhaps those on your dissertation committee) to support you. Another issue that can arise is a lack of responsiveness on the part of your advisor. This can manifest in not returning emails or failing to provide comments in a timely manner. Students can be overly deferential and worry about following up with faculty so as not to "bug" them. However, this is the first step you should take. If, after multiple attempts, you are still not getting a response, you may bring this to the attention of the department's Chair or Director of Graduate Studies so that they can intercede on your behalf.

One unfortunate cause for communication breakdowns between advisors and advisees can be due to implicit (unconscious) bias or a lack of shared cultural, social, or embodied

experience. Beyond the selection of advisees, unconscious bias can impact ongoing evaluations of the student's work, willingness to aid in networking, and levels of support when writing letters of recommendation. Exactly because this is an unconscious process, it can be hard to identify and root out when such bias is occurring. We all tend to use shortcuts or schemas when evaluating situations and people. This can lead to erroneous snap judgments; especially when stereotypes are at work. Such stereotypes can lead an advisor to project unwarranted positive or negative attributes onto a student based on the student's race/ethnicity, gender, disability, or sexual identity.

This is further problematized when advisors favor students that remind them of themselves. Also an unconscious process, people tend to see themselves in those that share their identity, similar attributes, or backgrounds. Because the discipline is still predominantly white men, white male students may benefit from replicating existing faculty demographics. Meanwhile, other students may have a harder time finding an advisor who they feel takes them and their work seriously. This process works both ways. Underrepresented students often feel more comfortable with faculty that share their attributes and experiences. This often results in those faculty members taking on larger advising loads than their colleagues which, in turn, can lead to less time spent with each advisee. While the increasing diversity of faculty may eventually counter the preponderance of these unconscious processes, both advisors and advisees should be aware of the role of implicit bias, its consequences, and ways to counteract the effects.

\section{Multiple Mentors}

Given the many roles an advisor can play, it is rare to find all the mentorship you need embodied in a single faculty member. You may have chosen your primary advisor due to your research interests; but discover that she isn't as useful when it comes to professionalization or providing emotional support. As a result, many departments organize professionalization workshops. Such a centralized approach has the benefit of equalizing graduate student training given the uneven mentorship that can occur as a result of differing advising styles. In terms of emotional support, peers - especially those that are going through the same program with you - can play a huge role. Previous cohorts can often provide students with advice based on their own experiences. Some programs have initiated cascading mentorship models in order to encourage this transmission of experience-based knowledge. Building horizontal networks among other graduate students is also a good idea as, assuming you stay in the academy, you will continue to be in each other's orbit for the rest of your career. For example, current fellow graduate students 
may one day be responsible for reviewing your manuscript, conference abstract, grant proposal, etc.

Your dissertation committee will provide varying insights into your research; but can also be leveraged for professional advice and other forms of mentorship. In addition, you will typically need at least three letters of recommendation when you go on the job market, and it helps to have all writers know you and your work well. It is also helpful to build your mentorship network beyond your primary advisor to other faculty members both within your department and at other universities. Several professional academic organizations - such as the American Political Science Association and the Association for Political Theory - have developed programs to match graduate students with a mentor on another campus. Some programs, recognizing ongoing issues within the academy, specifically provide support for women and underrepresented students. For example, the International Studies Association "Pay it Forward" program is designed to mentor early career women. External mentors from these programs help students to grow their network and provide an outsider's view of the issues one may be facing. It is often easier to vent to a faculty member that is not within one's own department. In addition, they have experience with multiple institutions - through their own graduate education and various job placements - so can provide insight into different approaches and norms. Finally, academic conferences offer a great opportunity to meet potential external faculty and peer mentors as there is a good chance that those attending the same panel have similar interests to your own.

Another issue that can arise is if an advisor retires, dies, or moves to another institution. Professors Emeriti will often continue to serve on dissertation committees after retirement. However, there is no obligation to do so. Similarly, the ability of faculty to take their advisees with them when they accept a new position is increasingly rare. While students can ask a potential advisor about plans to retire or move, the faculty member may genuinely not be able to predict what will happen over the course of the student's graduate training. In any of these scenarios, the student will need to choose a new advisor. For this reason, it is wise for an incoming student to assess her fit with more than one faculty member prior to accepting admission into that program. Even if the primary advisor does not change, students will want to identify multiple faculty members that can serve on their dissertation committee and provide additional mentorship.

\section{Conclusion}

This chapter has discussed the various aspects of professional and personal development to consider when selecting an advisor and mentor, and emphasized the importance of such a decision. Considering aspects as varied as rapport, availability, prestige, research fit, and professional support are essential throughout the process, and should all be weighed according to each students' preferences and needs. While the authors provide strategies to craft and make the most out of this support system, it is a long-term working relationship and there will be boundaries to create and expectations to set. The sooner each student begins these conversations, the better grasp they will have on how their advisor operates and how they would like their student to operate as well. 


\section{Additional Resources:}

https://www.apa.org/gradpsych/2014/11/mentoring-benefits

https://www.nature.com/articles/d41586-019-03535-y

https://www.isanet.org/Conferences/Special-Convention-Programs/Pay-it-forward

http://www.aspanet.org/mentor

https://associationforpoliticaltheory.org/

Noy, Shiri \& Rashawn Ray, “Graduate Student's Perceptions of Their Advisors: Is There Systematic Disadvantage in Mentorship?" in The Journal of Higher Education. Volume 83, Number 6, November/December 2012, pp. 876-914. https://muse.jhu.edu/article/488574 